\title{
Visibilidade política e controle da produção jornalística nos veículos de comunicação da Câmara dos Deputados
}

Este artigo tem como foco principal uma reflexão sobre as condições de visibilidade dos deputados federais brasileiros nas mídias legislativas mantidas pela Câmara dos Deputados. O objetivo é analisar não apenas como essa visibilidade efetivamente se realiza, mas também as limitações impostas pela atividade jornalística levada a cabo nos veículos da Casa. O embate entre duas lógicas diferentes - jornalística e política - na seleção das fontes e na tematização da mídia é um dos pressupostos desta análise. Como essa tensão constitui a produção informativa desses veículos é um dos pontos a serem compreendidos.

Para realização deste estudo, utilizamos algumas técnicas complementares de pesquisa: pesquisa bibliográfica sobre jornalismo e política, enfatizando a bibliografia sobre visibilidade política; observação-participante das rotinas de produção dos quatro veículos legislativos; entrevistas em profundidade com os profissionais dessas mídias ${ }^{1}$; análise da grade de programação das emissoras de TV e de rádio da Câmara ${ }^{2}$; e quantificação das citações de deputados realizadas em cada um dos veículos ${ }^{3}$.

\footnotetext{
A observação-participante das rotinas produtivas dos quatro veículos legislativos foi realizada pela autora entre 2007 e 2009 para sua tese de Doutorado em Ciência Política, defendida em 2010. As entrevistas em profundidade, realizadas com 43 profissionais da Secom, são outra técnica usada no trabalho.

2 As análises da grade de programação das duas emissoras fazem parte do trabalho do grupo de pesquisa "Comunicação pública no Legislativo: diretrizes editoriais e práticas profissionais", no qual a autora se integra. O grupo é filiado à linha de pesquisa "Cidadania e práticas democráticas de representação, participação política, comunicação e educação" do Programa de Pós-Graduação do Centro de Formação, Treinamento e Aperfeiçoamento (CEFOR) da Câmara dos Deputados.

3 A quantificação das citações foi realizada em colaboração com Aline Dias Paz, Antonio Teixeira de

- Revista Brasileira de Ciência Política, nº 6. Braślia, julho - dezembro de 2011, pp. 151-182
} 
Antes de ingressarmos na análise das questões que nos interessam, vejamos alguns dados sobre a atual organização da Secretaria de Comunicação (Secom) da Câmara dos Deputados, responsável pela gestão das mídias legislativas.

O sistema de comunicação da Câmara é gerido pela Secom, órgão que responde diretamente à Presidência da Casa. A implantação desse sistema começou em 1961, antes mesmo da Ditadura Militar. Naquele ano, foi criado o Serviço de Radiodifusão da Câmara dos Deputados, e o primeiro produto produzido foi um noticiário de 20 minutos para o programa oficial $A \mathrm{voz}$ do Brasil, em 1963. Até a década de 1990, a coordenação dos trabalhos era feita pela Assessoria de Divulgação Institucional e Relações Públicas (Adirp), órgão criado pela Resolução no 20, de 1971.

Depois de uma série de reformulações e adaptações feitas durante o processo de redemocratização, o sistema foi estruturado nos moldes atuais na década de 1990, e a Adirp foi transformada na Secretaria de Comunicação em 1998. Da própria justificativa para a mudança, assinada pelo então presidente da Câmara, consta que a denominação antiga fora dada na década de 1970 e estava "completamente superada". Segundo o documento, "a nova denominação adapta a área competente da Câmara dos Deputados à compreensão geral de suas funções, sobretudo no momento em que suas tarefas são ampliadas, com a criação da TV e da Rádio Câmara dos Deputados, entre outras iniciativas" (Câmara dos Deputados. Ato da Mesa no 96, de $19 / 06 / 1998)^{4}$.

Em 1998, foi criada a TV Câmara e, no ano seguinte, o boletim informativo foi transformado em um jornal diário, o Jornal da Câmara, em formato tabloide, com oito páginas. Ainda em 1999, foi criada a Rádio Câmara, emissora FM que transmite seu sinal no Distrito Federal e disponibiliza seu material informativo por meio da internet. Em 2000, o processo foi concluído com a estruturação da Agência Câmara, que transmite informação legislativa e o noticiário das atividades parlamentares via internet. Na década de 90, portanto, foi aperfeiçoada a comunicação direta com a população.

Barros, Maria Clarice Dias, Maíra Britto e Sílvia Mugnatto Macedo para análise dos veículos em quatro semanas alternadas de 2007.

4 Oficialmente, a TV Câmara e a Rádio Câmara foram criadas em outubro de 1997, mas só passaram a operar em 1998 e 1999, respectivamente. 
Além desses quatro veículos de comunicação, a Secom mantém uma série de ferramentas de comunicação para divulgação institucional e de informações, tais como as páginas informativas no Portal da Câmara, as visitas guiadas ou as atividades de relações públicas e de projeção da imagem da Câmara. Até 2010, a Secretaria de Comunicação da Câmara era composta por sete coordenações. Quatro delas eram os veículos propriamente ditos: Coordenação Agência Câmara de Notícias, Coordenação do Jornal da Câmara dos Deputados, Coordenação Rádio Câmara dos Deputados, Coordenação TV Câmara dos Deputados. As outras três eram: Coordenação de Divulgação, Coordenação de Jornalismo e Coordenação de Relações Públicas 5 .

A Coordenação de Divulgação dirige ações suplementares de formação de imagem nas áreas de internet, fotografia, noticiário em tempo real e demais mídias alternativas; supervisiona a produção de clippings e releases e o Serviço Fotográfico. Já a Coordenação de Relações Públicas (Corep) é responsável pela comunicação interna e pela Central de Relacionamento com o Cidadão, que mantém o Disque-Câmara, serviço telefônico de ligações gratuitas para a Câmara por meio de um número de 0800. Está subdividida em dez seções: Recepção e Turismo; Cerimonial; Projetos Especiais; Relações Institucionais; Normas e Protocolo; Eventos; Pesquisa e Publicações; Recepção Oficial; Visitação e Turismo; e Apoio de Relações Públicas.

A Coordenação de Jornalismo, por sua vez, é responsável por articular o trabalho de cobertura jornalística dos veículos da Câmara. Sua missão, conforme consta do próprio site da instituição, "é integrar o jornalismo da Rádio, da TV, do Jornal e da Agência de Notícias, para evitar duplicidade de ações e otimizar os recursos humanos disponíveis". A Coordenação também é responsável por serviços como: orientações aos veículos sobre pautas e coberturas; atendimento a parlamentares e a suas respectivas assessorias, a instâncias da Casa e a veículos de comunicação; acompanhamento do noticiário via TV e sites; checagem de informações sobre reuniões de comissões e agenda presidencial, entre outras; e contatos com a assessoria de comunicação da Presidência da Câmara.

Todos esses órgãos e setores da Secom têm como atribuição fundamental a gestão da comunicação que a Câmara dos Deputados realiza

Com as modificações na direção da Secom no início de 2011, algumas mudanças já foram anunciadas, entre elas a transformação de Agência e Jornal em um órgão apenas, com um diretor responsável. Mas a estrutura da Secom ainda está em processo de reestruturação pela nova equipe de diretores. 
com a sociedade brasileira ${ }^{6}$. Além da comunicação institucional com os públicos da organização, também são realizadas tarefas de informação pública e de jornalismo, por meio das mídias legislativas. Dessa forma, mais que a simples administração da imagem pública da instituição e da visibilidade dos parlamentares, a comunicação da Câmara tem objetivos públicos de prestar serviços de informação e comunicar conteúdos de interesse da população. Apesar do destaque, o interesse deste artigo está focado, como já ressaltamos, nas condições de visibilidade dos deputados nas mídias legislativas. Vejamos no que consiste e como essa visibilidade é, efetivamente, realizada.

\section{Visibilidade midiática}

A mídia é vista, por alguns autores, como uma "arma na controvérsia política” desde o seu surgimento (Marbut, 1971, p.15). Para outros, a mídia é mais um elemento que confere liderança aos atores políticos, como destaca Cook (1986, p. 203-204). Em ambas as análises, a mídia é vista como um instrumento e, em certa medida, como uma esfera que compete com a política na distribuição de poder entre os atores sociais.

Miguel e Biroli resumem as diferentes perspectivas teóricas sobre a relação entre mídia e política em quatro dimensões de influência política da comunicação nas sociedades contemporâneas, apontadas por vários analistas. Segundo os autores, a mídia: a) tornou-se o principal instrumento de contato entre a elite política e os cidadãos; b) transformou o discurso político e adaptou-o às suas preferências; c) é a principal responsável pela produção da agenda pública; d) tornou-se a principal gerenciadora da visibilidade pública, preocupação central dos atores políticos (Miguel e Biroli, 2010a, p. 9-10).

Com tantas atribuições midiáticas no jogo político, não é de estranhar que as organizações governamentais e sociais tentem promover o agendamento dos temas que lhes interessam a cada momento, ou seja, busquem visibilidade para seus atores e para as questões que mobilizam seus interesses por meio da comunicação. No contexto democrático das sociedades contemporâneas do final do século XX, entidades sociais e governamentais passaram a criar veículos de comunicação diretos com o público para diminuir sua dependên-

6 É importante ressaltar que os deputados têm suas próprias assessorias de comunicação e contato com o público, implantadas pelos funcionários contratados pelo gabinete parlamentar. Esses funcionários, na maioria dos casos, não são servidores de carreira do Parlamento, mas profissionais contratados diretamente pelo deputado. 
cia das empresas de mídia e melhorar uma relação sempre tensionada pelas disputas entre interesses econômicos e políticos. Este é o caso dos veículos legislativos criados no Brasil, incluídos na categoria "mídia das fontes" criada por Sant'Anna (2008).

Conforme enfatizam muitos autores, a visibilidade é a condição essencial para a disputa política nas atuais sociedades contemporâneas. Gomes ressalta que a democracia amplia a centralidade da esfera pública e das eleições, o que diminui a força da "política obscura", realizada nos bastidores e gabinetes e constitui "lugares e situações de publicidade como aqueles da decisão política autêntica e, posteriormente, legal” (Gomes, 2004, p. 263).

A busca por canais diretos de comunicação com o público, realizada nos veículos legislativos, está ancorada ainda em uma percepção do senso comum bastante difundida pelos próprios atores políticos: a de que a mídia divulga uma imagem negativa da esfera pública e faz com que o público se torne cada vez mais cínico e descrente da política. Essa hipótese da "espiral do cinismo" desenvolvida por Capella e Jamieson (1997) é uma das explicações apontadas por Miguel (2010) para a falta de crença na política e pode servir como justificativa para a criação de veículos e para o estabelecimento de estratégias de comunicação pelos atores políticos, especialmente aqueles ligados às instituições do Estado.

Mas o principal fator que justifica a criação dessas estruturas de comunicação parece ser, como ressaltam Miguel e Biroli, o fato de que a mídia é um elemento essencial na definição dos acontecimentos, opiniões, posições e atores que alcançarão a visibilidade.

Os meios de comunicação são percebidos ao mesmo tempo como fonte e índice de capital político. A partir de um conjunto de normas e valores que definem o que é noticiável e quem compõe a notícia, os meios de comunicação (especificamente o jornalismo) conferem distinção na medida em que tornam visíveis determinadas personagens. Ao mesmo tempo, a visibilidade é a "constatação", pelo jornalismo, de distinções e competências definidas com base em normas, valores e hierarquias que regem o campo da política e que os meios de comunicação absorvem (Miguel e Biroli, 2010c, p. 697).

Segundo os autores, os meios de comunicação de massa "ecoam nos discursos parlamentares, têm impacto na formação da agenda legislativa, fazem as vezes de fórum de discussão para as elites políticas" (Miguel e 
Biroli, 2010b, p. 2-3). Para eles, a visibilidade midiática é um componente importante na produção do capital político, pois contribui para ampliar ou reduzir as oportunidades do ator, interferindo nas carreiras políticas, conforme ressalta Bourdieu. Além disso, a mídia tem forte impacto "sobre a compreensão que os cidadãos comuns têm da política e do comportamento de atores específicos" (Miguel e Biroli, 2010b, p. 2-3). Por esse motivo, os autores concluem que a gestão da imagem pública, isto é, "a gestão da visibilidade pessoal na mídia, é uma preocupação central e permanente dos atores políticos, que não se limita aos períodos de competição eleitoral" (Miguel e Biroli, 2010b, p.2-3).

A disputa por visibilidade, portanto, é uma das principais estratégias políticas na era da comunicação de massa, inclusive nos períodos não-eleitorais (Weber, 2007; Gomes, 2004). A questão é que, para conseguirem visibilidade, os atores políticos precisam enfrentar o poder dos próprios jornalistas sobre a atividade informativa e a definição dos critérios de noticiabilidade.

Se o poder, na formulação de Maria Helena Weber, consiste na capacidade do sistema de dar visibilidade às suas versões e contagiar as demais redes de comunicação a repercutir e mobilizar a opinião pública em torno dos temas que lhe interessam (Weber, 2007, p. 25), nada mais natural que os deputados queiram interferir na produção de informação, entretenimento e propaganda institucional de interesse público dos veículos de mídia, especialmente dos legislativos.

Um elemento importante a destacar é o objetivo da comunicação política. Para Weber (2007), todo o discurso construído no campo da política destina-se à eleição, isto é, o objetivo final é sempre o voto. Na opinião dela, muito mais do que a necessidade de prestação de contas, os processos de comunicação inerentes aos regimes democráticos estão dirigidos à propaganda, seja "de um projeto político, de um sujeito, de um partido" (Weber, 2007, p. 39). E isso ocorre mesmo em períodos não-eleitorais, quando os sistemas de comunicação montados pelo Poder Público nas diferentes instâncias do governo buscam a visibilidade para os atores políticos e a credibilidade para seus discursos e versões dos fatos. Nesses períodos, há a produção de uma "informação cumulativa" dirigida à formação de imagem pública com incidência na decisão sobre o voto (Weber, 2007, p. 25). Uma rede voltada para a "eleição ininterrupta", nas palavras de Gomes (2004). 
A autora inclui as mídias legislativas entre as estratégias de comunicação política do Parlamento, juntamente com a manutenção de uma boa relação com a imprensa e a produção de fatos e notícias a partir do discurso político (Weber, 2007, p. 28).

O discurso político, aliás, é uma das principais ações dos atores políticos na busca da dominação legítima que garante o acesso da instância política ao poder e a conquista da legitimidade por meio de construção de opiniões, conforme analisa Charaudeau (2006). E também como garantia para a manutenção desse poder permanentemente ameaçado por "sanção física (golpe de Estado), institucional (derrubada do governo) ou simbólica (descrédito)" (Charaudeau, 2006, p.19). Nesse sentido, as mídias legislativas ajudam os atores políticos na construção dos discursos hegemônicos de explicação da realidade social. A transmissão das sessões e audiências parlamentares, a realização de entrevistas e matérias jornalísticas sobre o processo legislativo, e a mediação de debates entre os deputados auxilia, por consequência, na manutenção da legitimidade do sistema institucional.

Porém, é preciso ressaltar que a política que chega ao público é a "política em cena”, não a política de negociações entre os atores, conforme analisa Gomes (2004, p. 115). Em outros termos, o discurso e o posicionamento público do ator político sobre determinados temas são tão essenciais no jogo político contemporâneo quanto a negociação entre os atores para a divisão do poder. Desse modo, o fator "publicidade" sempre precisa ser considerado nos cálculos das negociações, envolvendo a visibilidade midiática, dominante nas atuais sociedades, o risco de exposição negativa, a popularidade e a imagem pública dos atores políticos (Gomes, 2004, p. 116).

Outro aspecto essencial nesta análise é reconhecer que as mídias legislativas, ainda que organizadas de acordo com as práticas da comunicação de massa, não têm o mesmo poder de agendamento ou a mesma visibilidade que os veículos comerciais no Brasil. A TV Câmara, por exemplo, tem sua transmissão realizada por meio de parabólicas, TV por assinatura ou em UHF em poucas capitais. Não é possível comparar seu poder de influência sobre a opinião pública com o poder exercido por Globo e Record, em resumo. Isso não impede, ao mesmo tempo, que ela sirva de fonte para os outros veículos e, indiretamente, chegue ao público nacional. Mas é preciso ter em mente as limitações no alcance de público dos veículos legislativos antes de prosseguirmos em nossa reflexão. 


\section{Atuação dos veículos da Câmara}

É um consenso entre os estudiosos da mídia legislativa que a intenção de parlamentares ou profissionais com as mídias legislativas não é apenas a transparência do Poder Legislativo. Como bem ressaltam alguns deputados, a comunicação direta com eleitores é um objetivo claro dos legisladores. E, além da transparência, os próprios servidores reconhecem uma série de outras funções das mídias da Câmara.

É inegável, contudo, que o acesso público à instituição e suas atividades cotidianas - sessões do Plenário, reuniões de CPI, audiências públicas das comissões, etc. - foi muito ampliado com a criação dos veículos de comunicação da Secom, especialmente a TV Câmara, que chega a todo o País por meio da TV por assinatura, e a Agência Câmara, por meio da internet. Ambas não podem ser consideradas mídias massivas, por conta dos suportes tecnológicos para sua divulgação. Ainda assim, levam informações a cidadãos que, antes delas, não tinham nenhuma forma de acesso à Câmara dos Deputados.

Além do banco de dados informatizado das proposições, que permite a pesquisa dos projetos originais, o fato de eles serem noticiados - e as notícias sobre determinados assuntos são enviadas pelo boletim diário da Agência Câmara aos representantes de várias entidades e também a pessoas físicas interessadas nos temas - permite a visibilidade das propostas. Ou seja, o fato de um projeto ser noticiado serve de alerta sobre sua existência aos grupos interessados ou não em sua aprovação. Em última instância, mobiliza socialmente grupos ou indivíduos, entidades e categorias profissionais, por exemplo. Como ressalta um profissional, "a Agência propicia, dá oportunidade de maior participação do cidadão comum no processo legislativo via internet”.

A partir dos relatos de profissionais, percebemos que as tensões entre os campos jornalístico e político aparecem agudamente nos veículos de comunicação do Legislativo, especialmente porque há uma disputa pelo poder de determinação dos critérios de cobertura. Isto é, O QUE e QUEM merece destaque nas mídias da Câmara.

A disputa não é exclusiva das mídias legislativas, também aparecendo nos veículos comercias por meio da pressão das fontes e dos próprios anunciantes. Entretanto, seu caráter é obviamente muito mais forte nos veículos da Câmara. E o motivo é o duplo status dos parlamentares como fontes de informação e como "superiores" hierárquicos dos servidores públicos que atuam na instituição. Apesar de não financiarem o funcionamento das mídias 
legislativas, são os deputados que definem os cargos de administração da Casa e os rumos de sua gestão.

Como ressalta Gomes sobre a mídia em geral, há uma constante disputa entre os vários atores sociais - governo, oposição, agentes do mercado, jornalismo econômico e público - para determinar as versões e a agenda econômica da opinião pública (Gomes, 2004, p.134). Até porque os agentes políticos sempre querem uma exposição midiática favorável, isto é, "querem aparecer nos jornais, nas revistas, no rádio e na televisão de modo que lhes renda o máximo de benefícios junto ao público" (Gomes, 2004, p.155) e também querem que seus adversários tenham exposição negativa.

Nos veículos legislativos, essa disputa pode assumir diferentes contornos pela percepção dos parlamentares de que há maior dependência dos jornalistas das fontes oficiais internas à Casa - sem deputados, não há matéria, na maioria dos casos - e também por eles atribuírem menor importância às mídias da Câmara, por terem menor audiência e credibilidade que as demais mídias. Dessa forma, para a ação estratégica dos deputados em busca da visibilidade pode ser melhor ter 10 segundos no Jornal Nacional do que um programa inteiro na TV Câmara.

Em relação à mídia convencional, é conveniente lembrar que muitos pesquisadores atribuem a ela um papel concorrencial com o Legislativo. Ao analisar a história de desenvolvimento da imprensa e do Parlamento na Inglaterra, Marbut afirma que a origem da força da notícia como arma nas controvérsias políticas está na disputa que foi travada entre o rei Charles I e o Parlamento no século XVII (Marbut, 1971, p.13). A luta da burguesia, que majoritariamente formava o Parlamento, usou os jornais contra o monarca, conferindo poder político às publicações e à publicidade feita por elas de debates e decisões. Com o passar do tempo e o aumento do poder parlamentar, os jornalistas passaram a buscar maior autonomia em relação aos políticos e, dos resultados dessa luta, surgiu o ideal moderno da liberdade de imprensa. Segundo o autor, um processo similar ocorreu nos Estados Unidos, onde o Congresso, já na segunda sessão, permitiu o acesso dos repórteres.

A autonomização crescente do campo jornalístico, tanto em relação ao político, quanto ao econômico, é um fato analisado por muitos pesquisadores e ressaltado sempre pelos profissionais. Robinson, por exemplo, lembra que o processo de crescente hostilidade da mídia norte-americana em relação ao Congresso detectado na década de 1980 foi considerado como uma 
"profissionalização da imprensa" pelos próprios jornalistas, enquanto os atores políticos chamavam o fenômeno de "canibalismo" (Robinson, 1981, p. 56). De qualquer forma, a maior autonomia da imprensa em relação à política contribuiu para ampliar a desconfiança mútua entre parlamentares e jornalistas. Nas sociedades contemporâneas, a comunicação controla a esfera de visibilidade pública, isto é, a única parte da cena pública que atinge praticamente toda a população (Gomes, 2004, p. 143). A mídia constitui uma espécie de "mundo, de horizonte de realidade" mais importante para a sociabilidade do que a experiência cotidiana (Gomes, 2004, p. 144).

Nesse sentido, os agentes do mundo da comunicação situam-se na entrada deste mundo, como se fossem um deus terminus, selecionando as pessoas, fatos, discursos e eventos que podem ser aí introduzidos, que podem ganhar existência midiática e organizando o modo como o podem ser (Gomes, 2004, p.144).

Em certa medida, é esse poder selecionador inerente à tarefa jornalística que os deputados querem obter. Como atores políticos, o controle da própria imagem para eles é crucial (Gomes, 2004, p. 286). Para isso, criam veículos legislativos como uma alternativa à cobertura da mídia convencional que eles consideram enviesada ou dramatizada (Cook, 1986, p. 204). Em sua análise dos canais legislativos do Brasil e do México, Dulce Queiroz também afirma que a motivação principal dos parlamentares "estava na busca de um contraponto ao discurso promovido pela mídia tradicional em torno do parlamento, calcado principalmente na denúncia e na espetacularização" (Queiroz, 2007, p. 200-201).

Entretanto, ao entrarem em funcionamento, as mídias legislativas acabam reduzindo o poder dos parlamentares de interferência na atividade, por dois motivos. O primeiro deles é que a própria logística da atuação jornalística impede que todas as decisões sejam tomadas com base nos critérios políticos mais desejáveis do ponto de vista dos deputados. Em certa medida, as rotinas jornalísticas acabam impondo seus próprios critérios e formas de organização dos fatos. O segundo motivo é que as atividades são realizadas por profissionais que também disputam a autonomia da profissão e lutam, constantemente, por uma independência nas decisões. Ou seja, os jornalistas atuam dentro do próprio campo profissional em busca da autoridade que lhes confere a competência profissional. Como ressalta Gomes, o uso do campo político para adquirir legitimidade gera descrédito entre os colegas 
e diminui a autoridade do profissional jornalista (Gomes, 2004, p. 56), enquanto a autoridade acumulada ao máximo assegura ao seu detentor o poder de definir as regras do jogo (Gomes, 2004, p. 54). Em resumo, a profissionalização das atividades de comunicação acaba retirando o poder da política e criando condições para maior autonomia do campo jornalístico. Como parecem perceber os profissionais,

Foi uma discussão interna mesmo. Eu não acredito, e não tem nenhum elemento que diga que algum Deputado pensou nessas regras. As pessoas daqui têm essa visão, do que é comunicação pública e de qual que é o nosso papel. E, de certa forma, a gente foi bem-sucedido nisso aí. Agora, é óbvio que uma vez ou outra existe uma tentativa de ingerência política, do mesmo jeito que em qualquer veículo comercial existe interferência direta do Departamento Comercial ou do dono do jornal. Ou você acha que os veículos comerciais também não têm assuntos do seu interesse? Me lembro, por exemplo, só para citar um exemplo, quando o governo endureceu a legislação para evitar a contratação de pessoas como pessoa jurídica, que é o que todos os veículos de comunicação fazem hoje em dia, quando o governo resolveu endurecer essa legislação todos os jornais comerciais desceram o cacete e fizeram uma grande campanha contra. Por quê? Porque atingia diretamente o interesse deles. Então, a gente não pode ser ingênuo ao ponto de achar que não existe interferência editorial em lugar nenhum. A gente tem uma relativa proteção contra isso porque tem 513 deputados com posições tão divergentes um do outro que isso acaba virando um anteparo para a gente. A gente não pode ser parcial, a gente não pode dar mais destaque para um deles, a gente não pode dar mais destaque para um partido, ou para uma comissão, ou para uma frente parlamentar. A gente é obrigado a ser equilibrado, entendeu? Então, isso é uma coisa interessante que tem aqui dentro (depoimento à pesquisadora).

Ao ressaltar que a mídia comercial também tem vários interesses, o jornalista apenas corrobora as análises teóricas que identificam as tensões entre os interesses divergentes de política, economia e mídia (Gomes, 2004). E chama a atenção para a disputa entre os diferentes campos sociais pela determinação das condições de visibilidade pública da política. Disputa constante que leva alguns autores a rejeitar a identificação da mídia como Quarto Poder. Como ressalta Neveu,

Postular a economia de um quarto poder é também esquecer que ao longo da história todos os poderes sociais souberam se adaptar a uma relação simbiótica com o jornalismo e institucionalizar seus ângulos, devido ao estatuto privilegiado de certas 
fontes, aos mecanismos de indexação e de filtragem favorecidos pela homologia entre editoriais e instituições (Neveu, 2006, p.196).

A citação de Neveu serve para lembrar que, apesar da autonomia conquistada, o jornalismo é fortemente influenciado pela cultura de cada sociedade, em cada época particular. Assim, as visões de mundo dominantes também aparecem com destaque na produção cultural, o que inclui o discurso jornalístico. Como prática social, o jornalismo não está imune às posições e ideias preponderantes nas demais esferas, assim como contribui para influenciá-las. Em nossa análise, portanto, não é possível desconhecer a dimensão da comunicação política em operação nas mídias legislativas. Sem levar em conta este aspecto, corremos o risco de deixar de lado um elemento fundamental na caracterização das tensões da atividade jornalística nos veículos da Câmara.

\section{Parlamentares nas mídias legislativas}

A principal forma de pressão usada pelos parlamentares é caracterizada por pedidos por "mais exposição". O caso mais ilustrativo durante o período analisado ocorreu em 2007. Em maio desse ano, uma reunião com todos os profissionais foi convocada pela direção para apresentação do Projeto de Valorização da Atividade Parlamentar (PROVAP). Na época, a reunião serviu para comunicar aos subordinados as medidas previstas no programa que, inclusive, já havia sido entregue aos integrantes da Mesa da Câmara.

$\mathrm{Na}$ ocasião, o diretor da Secom afirmou que o Provap não era de ordem pessoal, pois não havia sido inventado por ele. "Estou apenas respondendo à demanda da Mesa", foi sua declaração à época. Ele lembrou que os parlamentares eleitos no início do ano para a Mesa Diretora já haviam comentado em mais de uma ocasião que estavam preocupados com a comunicação da Câmara e com a imagem que a sociedade tem da instituição. "Já começamos a conversar com eles e vamos apresentar para vocês o plano que vamos apresentar para eles", continuou. "É uma discussão que está sendo levada à Mesa. Temos gordura pra queimar para atender à demanda de aumentar a presença de Parlamentares na mídia - nossa e dos outros", concluiu.

Durante o encontro, o diretor explicou que o programa não se destinava exclusivamente à equipe de jornalismo, pois das " 42 ações de impacto, só 18 são para o jornalismo". "Vocês vão continuar fazendo o que já fazem. Melho- 
rar a imagem da Câmara é tarefa para o pessoal de RP. O que não significa que os jornalistas não possam contribuir para a melhoria da instituição também”, enfatizou. Ele ressaltou que a inclusão da missão da Secom logo no início do documento entregue para os parlamentares foi feita para reforçar "que não mudaremos o que estamos fazendo". "Não deixaremos de ser isentos, apartidários, etc. por fazermos as ações sugeridas”, ressaltou. Mesmo assim, de acordo com as expectativas dos diretores, "se tudo for implantado, estimamos uma ampliação de 40\% na participação dos parlamentares na mídia”.

Um dos pontos mais interessantes de toda a discussão foi a admissão, pelos diretores, de que o Provap não era "um programa de valorização da Câmara, da instituição". O objetivo, segundo eles, era "ampliar a visibilidade das realizações dos Deputados Federais, colaborando com a formação de uma imagem institucional positiva”. A diretora da TV Câmara à época chamou a atenção de todos para a ambiguidade na redação dada ao objetivo. Segundo ela, "dar visibilidade às realizações dos deputados é diferente de dar visibilidade às atividades parlamentares". "Isso vai abrir oportunidade para que eles reclamem sempre por mais chances de aparecerem na emissora. Para eles, tudo o que fazem aqui na Câmara é importante e merece cobertura”, concluiu ela. A diretora lembrou ainda que fazia um verdadeiro trabalho de "doutrinação" para explicar aos parlamentares quais eram os critérios e rotinas de trabalho e, segundo ela, o Provap iria prejudicar ainda mais a relação com os deputados.

Alguns repórteres também expressaram seu descontentamento com o programa. Uma profissional da Rádio Câmara questionou duramente as medidas afirmando que "não somos assessores de imprensa dos deputados e institucionalizar isso é perigoso, porque se perde a qualidade da cobertura do jornalismo". Já uma repórter da TV também questionou se o programa não complicaria a situação dos jornalistas da Casa.

$\mathrm{O}$ diretor respondeu a ambas que o Provap era mais amplo que o jornalismo, que apenas $40 \%$ de suas ações diziam respeito ao jornalismo. Ele ressaltou ainda que "as pressões são o nosso dia-a-dia. Temos que administrar isso, ou ampliando em alguns casos ou desafogando um pouquinho a demanda, diluindo essas pressões" e citou como exemplo os programas da rádio criados para que os parlamentares tivessem mais um espaço para pronunciamentos no veículo (especialmente o Jogo Rápido, criado na época como uma das iniciativas do Provap). 
Durante a discussão, uma das repórteres chegou a sugerir que fosse feito um trabalho de assessoria de imprensa mais pró-ativo, em vez de reativo, para que essa imagem fosse melhorada sem interferir no trabalho dos veículos. O assessor de imprensa da Câmara à época interveio na discussão para afirmar que a angústia da repórter era a mesma dos deputados em relação à mídia comercial, mas que isso poderia ser atribuído também às ações dos parlamentares, que criam desconfianças entre os jornalistas. "Não somos nós quem vai mudar isso, nosso poder em mudar essa imagem é pequeno", destacou.

A preocupação com a imagem da Câmara é, obviamente, uma questão central para os setores da Secom que trabalham com Divulgação Institucional e Relações Públicas, assim como entre os parlamentares. Na época, o coordenador da área da Comunicação Institucional da Câmara afirmou que era preciso aproveitar "a estratégia de guerra e fazer da crise uma oportunidade de autoconhecimento e de promoção desses eventos", querendo dizer que a pressão parlamentar poderia ser bem aproveitada pela equipe. As peculiaridades das diferentes carreiras da Comunicação Social, especialmente o tradicional embate entre jornalistas e relações públicas, ficam claras no diferente posicionamento dos servidores da Secom.

Os próprios jornalistas reconhecem que a preocupação com a imagem institucional é algo importante. Para alguns, a preocupação da instituição com sua imagem e com o destaque para os valores republicanos que representa é legítima e necessária no regime democrático.

A Câmara dos Deputados tem valores para disseminar, a Câmara dos Deputados tem uma mensagem para passar. E isso não é propaganda de Parlamentar, isso não é para mentir, isso não é para florear. Isso é uma coisa que eu acho que é central para a questão da democracia. Eu vi numas pesquisas que o brasileiro, $60 \%$, acredita na democracia, mas o crédito que ele tem com as instituições democráticas é o oposto. E essa contradição é muito perigosa (depoimento à pesquisadora).

Entretanto, na opinião dos jornalistas a defesa da imagem da instituição não se confunde com a defesa das opiniões dos parlamentares ou com a divulgação apenas de informações positivas sobre eles, o que poderia caracterizar uso privado de veículos públicos. A ideia é que o uso privado de veículos estatais é um problema para o serviço público, pois, em realidade, 
os veículos de comunicação da Câmara pertencem a todos os brasileiros, que, indiretamente, pagam os servidores e sustentam sua estrutura por meio dos impostos. Por isso, o argumento da pluralidade e de mostrar sempre todos os lados de uma questão ganha força. Isso inclui mostrar também os argumentos do parlamentar, que precisa - legitimamente, num regime democrático - fazer a conexão com seus eleitores e, especialmente, o direito de o eleitor saber o que o seu parlamentar está fazendo.

Dessa forma, não é direito dos eleitores de um pequeno município obter, por meio da TV Câmara, informações sobre um deputado que, eventualmente, é candidato à prefeitura? Logicamente, um jornalista deverá argumentar que a forma mais correta do eleitor obter tais dados é por meio da cobertura jornalística dos fatos, e não por meio dos discursos do próprio parlamentar, interessado prioritariamente em sua eleição (ou então, que o eleitor deveria obter essas informações por meio do Horário Eleitoral Gratuito). Mas o eleitor não deve ter o direito de acesso ao discurso de todos os candidatos para poder escolher racionalmente com base nas promessas ou a partir das ações anteriores do político?

No caso dos políticos, é comum que eles tenham que fazer promessas a interesses específicos para que sejam eleitos, mas, ao mesmo tempo, as promessas podem ser um investimento informativo para os eleitores na hora da escolha do candidato (Manin, Przeworski e Stokes, 2006, p. 112-117). Isso tudo porque, apesar de não serem obrigados legalmente a manterem sua plataforma eleitoral, até porque pode ser racional modificar a política caso seja necessário, os políticos esperam que os eleitores possam reelegê-los se cumprirem suas promessas de campanha (Manin, Przeworski e Stokes, 2006).

Uma outra questão de fundo diz respeito ao poder de julgamento político. Quem deve julgar se o que está sendo feito é correto ou não é o próprio eleitor, à vista de seus interesses e demandas, não o jornalista, por seus próprios critérios ou interesses. Desse modo, assim como o deputado não pode cercear a informação que deve chegar ao eleitor, o jornalista não pode julgar ou censurar as manifestações dos parlamentares na tribuna da Câmara. Nas palavras de um dos profissionais da Secom,

Quem absolve ou condena é quem tem mandato parlamentar para isso. O fato de a gente passar em um concurso público para ser funcionário do Legislativo não nos dá o poder de julgar os parlamentares. Só quem pode julgar os parlamentares é o povo 
ou os parlamentares, que têm a delegação do povo. Nós, que somos jornalistas, e entramos aqui pelo concurso, nossa função não é essa. Nós somos pagos para divulgar, para noticiar, para acompanhar as atividades. Agora, quem julga, condena, não somos nós. Nós não temos delegação do povo para isso (depoimento à pesquisadora).

Seguindo o raciocínio da falta de mandato popular para o jornalista, o mais lógico seria a transparência total de todas as atividades legislativas ou a cobertura total de tudo o que ocorre no Parlamento. Ocorre que a cobertura total não é jornalismo. Jornalismo, ao contrário, pressupõe exatamente a seleção do que vai ser noticiado, aquilo que é mais relevante e mais importante entre tudo o que aconteceu no período. Há uma nítida questão de orientação, de ponto de vista. O jornalista seleciona para o público aquilo que ele merece, precisa ou quer saber. No entanto, quem faz isso é um selecionador profissional. A questão, portanto, parece ser exatamente QUEM vai definir os critérios para selecionar os fatos mais relevantes, mais importantes, mais úteis para o eleitor. Ao fim e ao cabo, deveria ele próprio ser o responsável por buscar as informações que realmente interessam a ele, o que se torna impossível devido ao arranjo e à estrutura dos próprios veículos de comunicação. Tornaremos a discutir essa questão com mais detalhes adiante.

O que está sob questionamento, portanto, é o papel das mídias legislativas de divulgarem para a população as opiniões dos parlamentares eleitos sobre os assuntos que interessam ao País. Além de os eleitores terem o direito de saberem o que pensam seus representantes, os demais cidadãos precisam saber quais são as opiniões que estão em jogo. A sociedade, por meio de suas organizações ou de alguns indivíduos, precisa se orientar sobre os interesses conflitantes em cada assunto estratégico.

Uma das profissionais da Secom lembra, a este respeito, que também almejava uma liberdade total ao ingressar na Câmara, "mas depois foi se dando conta de que a instituição é formada também pelos deputados, que nós servimos como intermediários entre eles e a população e que, por isso, precisamos levá-los em conta”. Além disso, ela observou que são os deputados os detentores dos votos populares, não os jornalistas. "E, por isso, como é que nós podemos ter a arrogância de acharmos que sabemos melhor do que eles o que é o interesse público?", ponderou.

Sobre a mesma questão, outra jornalista ressalta que, apesar desse argumento da legitimidade política alcançada pelo voto, os deputados formam um 
grupo específico, uma espécie de categoria, de "corporação", com interesses distintos dos interesses do resto da população - especialmente, o interesse bastante particular da reeleição -, além de ser governada por uma elite. Esta ideia encontra base no argumento da "mão-de-ferro das oligarquias partidárias" elaborado por Michels ${ }^{7}$ ou na própria ideia de burocracia de Weber, caracterizada pelos "políticos profissionais". Por isso, a jornalista defende a técnica do jornalismo como critério para atender ao interesse público, livre dos interesses partidários específicos.

Em outra ocasião, em junho de 2007, a equipe já havia sido reunida para discutir as modificações que estavam sendo feitas no Jornal da Câmara tiragem, proposta de edição semanal, etc. - por conta das novas orientações do Provap. Na ocasião, o Diretor da Secom destacou a dificuldade por que a publicação passa com tantas mudanças de critério, tão rápidas. "A cada legislatura, o jornal tem que se adaptar para atender à demanda inicial na nova Mesa”, explicou. "É o mesmo que ocorre nos demais veículos: muda o editor, muda a cara da publicação. No nosso caso, é a Mesa Diretora quem dá o tom, isto é, muda o critério editorial”, sentenciou. Esta fala do Diretor deixou realmente claro para toda a equipe que a condução dos veículos está na mão dos parlamentares, ainda que a prática profissional cotidiana abra muitos espaços para a busca de autonomia dos próprios jornalistas.

A seguir, tentaremos mostrar, de forma quantitativa, como os parlamentares aparecem nas mídias legislativas. Para isso, dividiremos nossa análise em dois pontos: quantificação das citações de deputados nos veículos legislativos; e análise das grades de programação semanais da TV e da Rádio Câmara.

\section{Citações de parlamentares nos veículos}

Dados levantados em 2007 mostram que a maior parte dos deputados citados nas matérias jornalísticas dos quatro veículos legislativos desempenha alguma função institucional dentro da Câmara. Em outras palavras, os parlamentares com maior visibilidade na produção jornalística das mídias legislativas detêm algum tipo de atividade institucional dentro da Casa,

Robert Michels analisou o Partido Social-Democrata Alemão (SPD) e apresentou sua tese sobre a relação entre democracia e organização, conceituando a "lei de ferro da oligarquia", ou seja, a tendência à centralização e à burocratização das organizações de massa. Segundo ele, é impossível uma organização realizar seu fim democrático, pois em toda a organização haverá uma elite, uma oligarquia que comandará os demais integrantes (Michels, 1982). 
participando da Mesa Diretora, das lideranças partidárias, das comissões permanentes ou, ainda, exercendo sua atividade legislativa por meio da autoria ou relatoria de projetos e proposições. São essas atividades que, aparentemente, constituem notícias sobre o Parlamento.

Tabela 1 - Percentual de citações por tipo de atores e veículo

\begin{tabular}{c|c|c|c|c|c|c|c|c}
\hline Tipos de atores políticos & TV & $\%$ & Rádio & $\%$ & Jornal & $\%$ & Agência & $\%$ \\
\hline Relator & 20 & 11,65 & 28 & 14,89 & 101 & 16,4 & 40 & 18 \\
\hline Presidente de comissão & 25 & 14,54 & 21 & 11,17 & 46 & 7,47 & 38 & 17 \\
\hline Autor de requerimento & 8 & 4,65 & 10 & 5,32 & 82 & 13,31 & 37 & 14,8 \\
\hline Autor de projeto & 12 & 6,97 & 10 & 5,32 & 46 & 7,47 & 4 & 1,7 \\
\hline Discurso em plenário & 0 & 0 & 0 & 0 & 174 & 28,25 & 0 & 0 \\
\hline Acusado em denúncias & 11 & 6,39 & 13 & 6,92 & 11 & 1,78 & 11 & 5 \\
\hline Integrante da mesa & 0 & 0 & 2 & 1,06 & 5 & 0,81 & 2 & 0,99 \\
\hline Presidente da Câmara & 36 & 20,9 & 45 & 23,94 & 44 & 6,98 & 26 & 11,51 \\
\hline Líder partidário & 60 & 34,9 & 59 & 31,38 & 108 & 17,53 & 68 & 31 \\
\hline $\begin{array}{c}\text { Total geral de citações } \\
\text { de cada veículo }\end{array}$ & 297 & & 286 & & 1025 & & 413 & \\
\hline
\end{tabular}

Fonte: Bernardes e Barros (2007).

Ao calcularmos o percentual total de citações identificadas nos veículos legislativos nas quatro semanas de análise chegamos ao número de 2021 citações $^{8}$. Sobre as citações da Agência Câmara, é importante informar que não foram incluídas na amostra as matérias referentes aos projetos apresentados e que destacam as votações dos projetos nas comissões. Nossa análise ficou centrada nas matérias de cobertura diária das atividades para que pudéssemos observar a utilização de fontes menos ligadas ao processo legislativo. É necessário destacar que a Agência concede bastante espaço para fontes externas ao Poder Legislativo, uma vez que a cobertura de audiências públicas e seminários promovidos na Câmara recebe atenção em suas páginas.

Já em relação ao Jornal da Câmara, houve a inclusão das matérias que tratam do debate ocorrido em Plenário, grande parte do material publicado.

8 Foram incluídas as citações indiretas, em que o parlamentar é citado pelo jornalista, e as diretas, as chamadas sonoras ou depoimentos. 
Apesar de os líderes terem prioridade de pronunciamento durante a votação das matérias, os demais deputados utilizam os espaços destinados às breves comunicações para suas declarações. Essas falas são noticiadas no programa "A voz do Brasil" e reproduzidas pelo Jornal sob o nome de "Pinga-fogo", versando sobre temas diversos. Os parlamentares também podem interferir durante a votação com questões de ordem formuladas à Mesa. Tais intervenções durante a ordem do dia e os pronunciamentos no espaço do Pequeno e do Grande Expediente, que dependem de um sorteio e contam com tempo certo de duração, previstos regimentalmente, ajudam a explicar o maior número de citações identificadas como "discurso em Plenário".

É bom lembrar ainda que TV e Rádio transmitem ao vivo as sessões do Plenário, o que significa que os pronunciamentos não são aproveitados diretamente na produção jornalística diária, exceto quando fatos excepcionais ocorrem durante as sessões, como a votação de uma matéria importante, por exemplo. Mesmo assim, os repórteres tentam gravar uma entrevista exclusiva com os parlamentares envolvidos, em vez de simplesmente reproduzir seus pronunciamentos na tribuna. Não é de estranhar, portanto, que as emissoras não tenham citações identificadas como "discurso em Plenário".

A Agência, por sua própria característica hipertextual de veículo digital, também não publica o material jornalístico produzido a partir dos discursos em Plenário, apesar de ter o noticiário em Tempo Real (isto é, online) das decisões e do encaminhamento das votações. No meio digital, o internauta tem as opções de acessar diretamente o conteúdo dos demais veículos (TV, rádio ou jornal) ou até mesmo acompanhar as notas taquigráficas de cada sessão. Não há necessidade, portanto, de noticiar dados redundantes. Nesse contexto digital, o noticiário das decisões do Plenário serve como guia para que o usuário acesse os demais conteúdos.

Como regra geral, o maior número de citações é dedicado aos líderes, o que mostra a importância da instituição da liderança para a ação coletiva no Parlamento. Na Agência, na TV e na Rádio mais de 30\% das citações se enquadram nessa categoria. Somente o Jornal não seguiu essa indicação, com maior número de citações para os discursos em Plenário, não noticiados nos

Na época de quantificação das citações, a TV Câmara não tinha em sua grade o programa "Fatos e Opiniões", que consiste num resumo das discussões e votações realizadas durante a semana no Plenário. Atualmente, este programa amplia o número de citações de parlamentares na grade semanal da emissora e enfatiza, exatamente, os discursos proferidos em Plenário. 
demais veículos pelos motivos já explicitados. Os líderes ocupam a segunda posição em número de citações no jornal, com 17,53\%.

Em todos os veículos, o deputado mais citado é o presidente da Câmara. No total, ele recebeu 151 citações, o que corresponde a 7,47\% de todas as citações para parlamentares nos quatro veículos. O maior número de citações foi feito na Rádio, com 29,80\%, enquanto a Agência o citou somente $17,22 \%$. Para se ter uma ideia do montante de tempo e espaço destinado ao presidente, todos os líderes partidários foram citados 295 vezes nos quatro veículos, o equivalente a $14,6 \%$ do total das citações.

Tabela 2 - Total de deputados citados em cada veículo

\begin{tabular}{c|c}
\hline Veículo & No de deputado citados \\
\hline Jornal & 348 \\
\hline Agência & 201 \\
\hline TV & 148 \\
\hline Rádio & 119 \\
\hline
\end{tabular}

Fonte: Bernardes e Barros (2007).

O veículo que citou mais deputados diferentes foi o jornal, com 349 nomes, mais de 68\% do total de integrantes da Câmara. Agência citou 201 deputados diferentes, enquanto TV e rádio citaram, respectivamente, 148 e 119 parlamentares. Nos quatro veículos, 379 diferentes deputados foram citados nas semanas de análise, número equivalente a 73,88\% dos parlamentares da Câmara. Do mesmo modo, a maior média de citações para cada deputado também foi encontrada no jornal: 2,94. A rádio citou cada deputado, em média, 2,4 vezes. Agência alcançou o índice de 2,05, enquanto a TV teve média de apenas 2,0068 citações por deputado.

Além da média, outro dado interessante é o número de citações por deputado em cada veículo. Em todos os veículos, a maioria dos deputados foi citada apenas uma vez. Na TV, esse índice chega a 64,18\%, enquanto somente $11,49 \%$ dos deputados mereceram mais de quatro citações. Rádio e agência também tiveram mais de $50 \%$ dos deputados citados apenas uma vez. No outro extremo, o jornal citou apenas uma vez 35,65\% dos parlamentares que apareceram em suas páginas. Diferentemente dos outros veículos, $24,95 \%$ dos deputados aparecem mais de quatro vezes nas páginas da publicação. 
A partir dos dados coletados, podemos concluir que o aparecimento de um deputado na mídia legislativa deve-se, principalmente, às atividades parlamentares exercidas por ele. Em alguns casos, essas atividades são usadas como pretexto para divulgação do parlamentar nos veículos de comunicação da Casa. Por exemplo, um deputado pode requerer a realização de uma audiência não somente com a intenção de debater um tema e a marcar posição diante de um público específico, mas também na esperança de que o evento seja divulgado pela mídia digital da Casa. Do mesmo modo, os parlamentares sabem que os discursos em Plenário são transmitidos ao vivo pela Rádio e pela TV e muitos deles serão noticiados no Jornal da Câmara. Várias vezes eles chegam a citar durante seus pronunciamentos o desejo de que "seja dada publicação ao discurso nos veículos da Casa”.

Destacamos aqui que a quantificação das citações foi realizada no material jornalístico diário produzido pelas emissoras, mas desconsiderou as produções específicas de debates, entrevistas e de cunho cultural, tanto da rádio quanto da TV. A inclusão desses programas na amostra com certeza traria modificações substanciais nos resultados, mas não constituiu o foco desse levantamento, centrado na produção noticiosa diária e não nas produções mais atemporais dos veículos.

Vejamos, na sequência, qual o espaço dedicado na programação de rádio e TV Câmara para as transmissões do Plenário e demais atividades jornalísticas. É o tema dos dois próximos itens.

\section{Visibilidade na programação da TV Câmara}

A TV Câmara funciona 24 horas por dia, sete dias por semana. Pela definição da Lei de Cabo (Lei 8977/1995), sua função prioritária é transmitir, ao vivo, as sessões do Plenário da instituição. O canal transmite também, ao vivo ou gravadas, reuniões e audiências públicas das 20 comissões permanentes e das comissões temporárias, como comissões parlamentares de inquérito (CPIs) ou comissões especiais destinadas a avaliar projetos específicos. Além disso, a programação inclui telejornais, programas de debates e entrevistas, documentários e outros formatos televisivos. A maior parte dessa produção é realizada por profissionais da Câmara dos Deputados, mas também vão ao ar coproduções, especialmente documentários e filmes em curta-metragem.

A grade de programação da TV Câmara é composta por 24 programas, entre noticiários, debates, entrevistas, documentários, programas culturais, musicais, 
filmes em curta-metragem e até mesmo um programa de auditório voltado para o público jovem (Câmara ligada). Além desses, são produzidos nove interprogramas, chamados assim por serem produções curtas, de no máximo sete minutos, que servem para preencher a grade entre os demais programas. Produções promocionais, compilações de matérias jornalísticas veiculadas pela emissora ou pequenas séries documentais que abordam diferentes temas são alguns exemplos de interprogramas. A maior parte deles é feita pela própria equipe de profissionais da emissora, especialmente os programas jornalísticos, os debates e as entrevistas. Já os documentários e filmes são, em sua maioria, coproduções com outras emissoras ou com produtoras independentes.

Na Tabela 3 apresenta-se o levantamento semanal da grade da emisso$\mathrm{ra}^{10}$, classificando os programas em cinco diferentes gêneros de produção: jornalismo, debates/entrevistas, programas culturais, documentários e transmissão de Plenário/comissões. Sobre a relação entre os gêneros e total de horas destinado a cada um, observa-se que predomina a transmissão de Plenário e Comissões, com quase um terço do total semanal de horas de programação da emissora $(27,9 \%)$.

Tabela 3 - Gêneros de programação da TV Câmara

\begin{tabular}{c|c|c|c|c|c|c|c|c|c}
\hline Gêneros/hora & Seg. & Ter. & Qua. & Qui. & Sex. & Sáb. & Dom. & Semanal & Percentual \\
\hline Jornalismo & $4 \mathrm{~h}$ & $3 \mathrm{~h} 30$ & $3 \mathrm{~h} 30$ & $3 \mathrm{~h} 45$ & $3 \mathrm{~h} 30$ & $7 \mathrm{~h} 15$ & $7 \mathrm{~h}$ & $32 \mathrm{~h} 30$ & $19,3 \%$ \\
\hline Debates/Entrevistas & $9 \mathrm{~h} 45$ & $5 \mathrm{~h} 45$ & $5 \mathrm{~h} 45$ & $7 \mathrm{~h}$ & $5 \mathrm{~h} 45$ & $3 \mathrm{~h} 15$ & $4 \mathrm{~h}$ & $41 \mathrm{~h} 15$ & $24,5 \%$ \\
\hline Programas culturais & $2 \mathrm{~h} 30$ & $2 \mathrm{~h} 30$ & $1 \mathrm{~h} 30$ & $1 \mathrm{~h} 30$ & $3 \mathrm{~h} 30$ & $8 \mathrm{~h}$ & $7 \mathrm{~h}$ & $26 \mathrm{~h} 30$ & $15,7 \%$ \\
\hline Documentários & $1 \mathrm{~h} 45$ & $1 \mathrm{~h} 15$ & $2 \mathrm{~h} 15$ & $45 \mathrm{~min}$ & $3 \mathrm{~h} 15$ & $3 \mathrm{~h}$ & $6 \mathrm{~h}$ & $18 \mathrm{~h} 15$ & $10,8 \%$ \\
\hline Diversos & 0 & 0 & 0 & 0 & 0 & $2 \mathrm{~h} 30$ & 0 & $2 \mathrm{~h} 30$ & $1,4 \%$ \\
\hline Plenário e Comissões & $6 \mathrm{~h}$ & $11 \mathrm{~h}$ & $11 \mathrm{~h}$ & $11 \mathrm{~h}$ & $8 \mathrm{~h}$ & 0 & 0 & $47 \mathrm{~h}$ & $27,9 \%$ \\
\hline TOTAL & $\mathbf{2 4 h}$ & $\mathbf{2 4 h}$ & $\mathbf{2 4 h}$ & $\mathbf{2 4 h}$ & $\mathbf{2 4 h}$ & $\mathbf{2 4 h}$ & $\mathbf{2 4 h}$ & $\mathbf{1 6 8 h}$ & $100 \%$ \\
\hline
\end{tabular}

Fonte: Barros, Bernardes e Lemos (2010).

A TV Câmara mantém sua missão essencial: dar transparência e visibilidade para os discursos e votações do Plenário e das comissões temáticas da Câmara dos Deputados. Semanalmente, das 168 horas de programação ininterrupta, 47 são dedicadas à transmissão ao vivo e gravação das reuniões

10 O levantamento diz respeito a uma semana do segundo semestre de 2009. 
que ocorrem na Casa. Nas segundas-feiras, a transmissão ao vivo ocorre durante a tarde, já nas sextas-feiras as sessões do período da manhã são transmitidas. Nos demais dias, o Plenário tem prioridade das $10 \mathrm{~h} 30 \mathrm{~min}$ às $12 \mathrm{~h} 30 \mathrm{~min}$ e das $14 \mathrm{~h}$ às $19 \mathrm{~h} 30 \mathrm{~min}$, horários em que normalmente ocorrem as sessões. As tardes de sexta e as madrugadas de terça, quarta e quinta são destinadas para reprises do próprio Plenário ou das comissões reunidas durante a semana.

Obviamente, a transmissão do Plenário é imprevisível, como toda transmissão ao vivo. As reuniões podem se estender noite adentro, o que impede a exibição dos programas previstos. Em outros dias, as sessões podem simplesmente ser mais curtas ou nem ocorrer, o que obriga a emissora a colocar outras produções no ar, geralmente as íntegras de reuniões das comissões temáticas. Essas íntegras também são muito usadas para preencher a grade normal nos períodos de recesso parlamentar, quando não há sessões diárias no Plenário (em janeiro e na segunda quinzena de julho).

De qualquer modo, as transmissões, ao vivo ou gravadas, das reuniões do Plenário e das comissões ocupam quase $28 \%$ da grade semanal da emissora, podendo variar, conforme já mencionamos, de semana para semana. Em 2009, o gerente do Núcleo de Conteúdo da emissora estimava que apenas $25 \%$ das reuniões das comissões eram exibidas semanalmente, ao vivo ou gravadas. Nos períodos de recesso, aproximadamente a metade das reuniões acaba sendo veiculada, para preencher a grade. Sobram 25\% das reuniões que não são serão exibidas no canal.

O segundo tipo de programa mais veiculado pela TV Câmara são as produções voltadas para o debate e as entrevistas, que ocupam $24,55 \%$ da grade. Algumas produções conjugam elementos dos dois gêneros - opinião e jornalismo -, com um apresentador que induz o debate dos participantes por meio de perguntas e apresentação de reportagens sobre o assunto (Expressão nacional) ou com a participação de cidadãos no próprio estúdio (Participação popular). Em todas as produções há participação dos parlamentares, e dois programas destinam-se exclusivamente a eles: Brasil em debate, no qual dois deputados discutem um tema de relevância na pauta do Congresso; e Palavra aberta, em que um parlamentar analisa um assunto de sua preferência.

Segundo a definição adotada pela própria equipe, tais produções e também os documentários, que preenchem 10,8\% da programação semanal, 
são considerados "programas de reflexão". Segundo o gerente do Núcleo de Conteúdo, esses programas privilegiam a habilidade interpretativa do público, promovendo uma reflexão sobre diferentes temas.

O jornalismo propriamente dito, com noticiários e flashes informativos ao longo da programação, ocupa 19,34\% da programação, com mais de 30 horas semanais de informação e compõe o que a equipe denomina de "programas informativos". "São aqueles programas em que aparece o fato puro, sem análise ou opinião", explicou o profissional da emissora. As duas principais produções do gênero na emissora são os telejornais Por dentro da Câmara - exibido de terça a quinta-feira, às $10 \mathrm{~h}^{11}$, e o Câmara hoje, exibido de segunda a quinta-feira, às $21 \mathrm{~h}$.

Verifica-se ainda na grade de programação da emissora uma divisão entre os gêneros nos dias da semana. De segunda a sexta-feira, com as transmissões do Plenário e das comissões, há pouco tempo para produções culturais e programas musicais, que são concentrados nos finais de semana, respeitando a rotina de trabalho das instituições públicas. No total, os programas culturais ocupam $15,77 \%$ da grade de programação da emissora. Nos finais de semana também há um aumento do número de programas jornalísticos, mas isso se deve às reprises das produções exibidas ao longo da semana.

A análise da grade da TV Câmara mostra que há grande espaço de visibilidade para os parlamentares na emissora, ainda que o jornalismo apresente um menor número de citações de deputados (297) do que as produções do jornal (1025) e da agência (413), conforme vimos no item anterior. Enquanto a transmissão das atividades legislativas ocupa quase um terço da programação, jornalismo diário e programas de debates e entrevistas somam 43,8\% das produções. Ou seja, os programas que privilegiam declarações e aparições dos parlamentares constituem mais de $70 \%$ da grade de programação semanal da emissora $(71,7 \%)$.

\section{Visibilidade na Rádio Câmara}

A grade da programação da Rádio Câmara é composta por 31 programas, entre noticiário, entrevistas, Voz do Brasil, transmissão do Plenário, campanhas educativas (spots), programas culturais e música. A programação radiofônica segue o mesmo princípio da televisão, privilegiando o jornalismo

11 Em 2010, o telejornal da manhã ganhou duas edições de terça a quinta-feira (às 10h e às 12h30) e passou a chamar-se Câmara hoje também. 
e a transmissão das atividades parlamentares de segunda a sexta e deixando a programação para o final de semana, quando a Câmara não funciona.

O noticiário diário está dividido em boletins que variam de dois minutos e meio a oito minutos e que vão ao ar de hora em hora, e um jornal matutino, o Câmara aberta. As campanhas e o "rádio serviço" foram contados como um único programa, apesar de tratarem de diversos temas. O noticiário, as entrevistas, as campanhas e os 20 minutos da Voz do Brasil são produzidos pela equipe de redação da rádio. Além dos boletins de hora em hora, os repórteres podem entrar no ar a qualquer momento para divulgar notícias em tempo real.

\section{Tabela 4 - Gêneros de programação da Rádio Câmara}

\begin{tabular}{c|c|c}
\hline Gêneros & Percentagem semanal & Percentagem fim de semana \\
\hline Jornalismo & 10,37 & 9,3 \\
\hline Entrevistas & 2,15 & 0 \\
\hline Voz & 4,17 & 0 \\
\hline Plenário & 20,83 & 1,52 \\
\hline Spots & 1,68 & 68 \\
\hline Música* & 53,3 & 21,18 \\
\hline Culturais & 7,5 &
\end{tabular}

*mais a publicidade institucional

Fonte: Mugnatto e Bernardes (2010).

Na Tabela 4, incluímos os 300 minutos de transmissão do Plenário por dia, correspondentes ao tempo da sessão ordinária da Câmara, o que significa mais de $20 \%$ da grade de programação entre segundas e sextas-feiras. Mas, muitas vezes, são convocadas sessões extraordinárias, e a programação é interrompida novamente para a transmissão dos debates. Durante a transmissão do Plenário, um jornalista (âncora) narra os eventos para o ouvinte que acabou de ligar o rádio e, eventualmente, chama os repórteres para uma rápida intervenção sobre notícias que estão acontecendo no mesmo momento em outros locais da Casa, como comissões temáticas e comissões parlamentares de inquérito.

Em comparação à TV Câmara, percebemos que a rádio tem um percentual menor de tempo destinado à transmissão ao vivo das atividades legislativas. A diferença principal é que a emissora não retransmite as reuniões das comissões permanentes, como faz a TV. Por este motivo, o percentual do 
Plenário alcança apenas $20 \%$ da programação nos dias de semana, contra $28 \%$ da TV Câmara.

Durante a semana, dias em que há reuniões dos parlamentares e audiências públicas, a informação jornalística e a transmissão do Plenário, principais espaços para a citação dos deputados e sua participação direta na produção da emissora, chegam a 37,52\% da programação da Rádio Câmara. Mesmo assim, grande parte do horário, especialmente durante a noite e a madrugada, é preenchida com música, que alcança $53,3 \%$ da grade entre segunda e sexta-feira.

Um ponto interessante é que, entre os cinco programas de entrevistas, apenas dois são feitos exclusivamente com deputados. Os demais abordam temas de interesse da sociedade que, geralmente, já passaram ou vão passar por alguma discussão na Câmara e trazem especialistas nos assuntos abordados. É o caso da Reportagem especial, que trata de um tema e é veiculada em partes durante a semana. Além disso, a Rádio não conta com programas de debates entre parlamentares ou entre representantes da sociedade civil, como a TV Câmara. Provavelmente, porque é mais difícil veicular esse tipo de produção no rádio, que não conta com a imagem para auxiliar na compreensão dos debates.

Nos finais de semana, a programação musical predomina ainda mais, completando 68\% do tempo de veiculação, além dos programas especiais na área de cultura. Somada aos culturais, a programação musical alcança quase 90\% do tempo da emissora aos sábados e domingos (89,18\%). Os programas culturais disponíveis na programação somam 18, ao todo. Colaboradores fazem programas especiais sobre jazz, samba e música contemporânea, entre outros gêneros musicais.

A Rádio Câmara tem ainda um acordo com as assembleias legislativas para disponibilizar na página da Câmara na internet matérias produzidas pelas equipes de jornalismo destas instituições. Eventualmente, quando há interesse mais geral, o material pode ser aproveitado no noticiário da emissora.

Os spots, que têm uma grande aceitação entre as rádios parceiras ${ }^{12}$, são colocados no ar nos intervalos da programação. Em janeiro de 2010, estavam no ar nove campanhas, com 42 spots de 30 segundos cada. Mas, na

\footnotetext{
12 A Rádio Câmara tem um serviço de radioagência por meio da internet no qual disponibiliza toda a sua programação para que emissoras de todo o País possam fazer download e veicular programas e matérias jornalísticas em suas regiões. As emissoras cadastradas no site da Rádio são denominadas "rádios parceiras". Em 2010, o número de rádios parceiras aproximava-se de 1,5 mil.
} 
internet, as rádios parceiras tinham à disposição, pelo menos, 31 campanhas diferentes. Outro produto sem periodicidade definida são as radionovelas, que buscam trabalhar com temas mais complexos e atemporais, como o processo de aprovação do Orçamento, em uma linguagem mais acessível para a população em geral.

De forma geral, percebe-se que a participação dos parlamentares é menor na rádio do que na TV Câmara. Isso se deve ao fato de que a grade da rádio é composta, de forma majoritária, por uma programação musical e cultural, especialmente nos finais de semana. E ainda, que suas produções dedicadas às entrevistas e debates sobre assuntos polêmicos ou em discussão no Legislativo variam o número de fontes, abrindo maior espaço para especialistas da sociedade civil sobre os assuntos abordados. Mesmo assim, o número de citações de parlamentares na emissora é apenas ligeiramente inferior ao da tevê (286 X 297), ainda que a Rádio Câmara seja o veículo legislativo com menor quantidade de parlamentares citados em sua produção jornalística (119). Isso também é reflexo, em parte, de uma cobertura mais centrada no Salão Verde e na repercussão de temas destacados pela mídia comercial e com menor ênfase para as audiências e reuniões das comissões, que merecem uma cobertura jornalística mais extensa na Agência e no Jornal da Câmara.

\section{Conclusão}

Analisados em conjunto, tanto os dados empíricos de caráter quantitativo, quanto os qualitativos apresentados neste artigo, coletados ao longo dos últimos anos pela autora em conjunto com os demais membros do grupo de pesquisa que integra, mostram que os parlamentares obtêm grandes oportunidades de visibilidade política nas mídias mantidas pela Câmara dos Deputados. Mesmo assim, elas não parecem ser suficientes para a construção de uma estratégia de visibilidade pública dos atores políticos, conforme demonstram os depoimentos dos profissionais e a própria observação das rotinas produtivas desses veículos. As pressões por mais visibilidade e pela condução do processo de seleção de temas, enfoques e fontes da produção jornalística são constantes.

Se a visibilidade que a política de massas demanda coloca os meios de comunicação no centro da dinâmica política, conforme ressaltam Miguel e Biroli (2010b, p. 2), a mídia legislativa assume uma importância central para os atores políticos. A definição, pelos veículos de comunicação, dos temas 
que merecem destaque na agenda pública constrange os políticos e atores institucionais a buscarem sempre mais espaço e participação na mídia (Miguel e Biroli, 2010b, p. 2). Mas a oportunidade de gestão da própria imagem é sempre dificultada pela ação jornalística, que caracteriza uma espécie de barreira às intenções políticas dos atores institucionais. No caso das mídias mantidas pelo Parlamento, essa tensão entre o critério jornalístico e o critério político é ainda mais aguda, uma vez que os parlamentares se sentem donos desses veículos por fazerem parte da instituição que os mantêm e por serem detentores do mandato representativo.

A visibilidade diferenciada dos temas que compõem a agenda da mídia está relacionada ao entendimento do que é politicamente relevante. E essa relevância se conecta, por sua vez, à centralidade assumida por atores e práticas políticas específicos. Nesse sentido, agenda e concessão de voz são dois aspectos de uma compreensão fundamental, a de que a política democrática é feita em determinados espaços e por determinados atores, ainda que suas práticas sejam, rotineiramente, submetidas ao escrutínio da população em geral (Miguel e Biroli, 2010b, p. 19).

As mídias legislativas, portanto, constituem um espaço social importante para a configuração da visibilidade política em seus dois aspectos principais: concessão de voz e poder de agenda, até porque servem como fontes primárias de informação para os demais veículos de comunicação e para a sociedade civil organizada. Entretanto, como percebemos na análise das citações de cada veículo da Câmara, não são todos os parlamentares que merecem atenção das mídias legislativas. Geralmente, aparecem aqueles que são detentores de cargos e de algum tipo de poder institucional dentro da instância legislativa, com especial privilégio para o presidente da Câmara e para os líderes partidários.

Muitos estudos sobre a relação entre mídia comercial e fontes destacam exatamente o "oficialismo" que domina as redações (Amaral, 2002; Hackett, 1993; Rodrigues, 1993). Ou seja, os pesquisadores criticam a predominância de escolha das "fontes oficiais", geralmente ligadas ao governo. Em um ambiente como a Câmara, por definição, todas as fontes são oficiais, mesmo aquelas que participam de audiências públicas - membros dos demais poderes, representantes da sociedade civil, especialistas, etc. O oficialismo, nesse caso, reside na predominância da escolha dos líderes para falar em nome das bancadas e no presidente da Casa para falar em nome da instituição. 
Assim como na mídia comercial, é importante ressaltar que o oficialismo, além de facilitar o trabalho jornalístico - pois o jornalista não precisa buscar novas fontes para cada assunto - e garantir o atendimento ao critério temporal da produção - poupa tempo -, serve como meio de proteção para os jornalistas. Em caso de críticas, o jornalista sempre poderá dizer que as informações vieram de uma fonte oficial, que tem obrigação com a veracidade e a precisão tanto quanto o próprio jornalista.

De qualquer forma, é preciso salientar uma observação de Miguel e Biroli sobre a mídia convencional que parece também se aplicar aos veículos da Câmara: "o discurso jornalístico da mídia de massas simula a pluralidade concentrando-se em poucos atores, que representam posições que esgotariam os debates" (2010b, p.3). Apesar de constituírem um espaço privilegiado de visibilidade para os deputados, as mídias legislativas acabam reproduzindo os critérios que norteiam a produção jornalística no geral e centrando seu discurso em fontes que, geralmente, já detêm algum poder institucional. $\mathrm{O}$ que não configura uma estratégia de auxílio à pluralidade midiática, condição já destacada por muitos autores para maior qualificação do regime democrático (Miguel, 2004).

Por outro lado, é inegável que o espaço dedicado à cobertura das atividades do Legislativo por essas mídias é muito superior ao que geralmente é dedicado aos assuntos políticos nas emissoras e veículos comerciais, o que pode favorecer não apenas a disseminação de informações sobre o Parlamento, mas também a própria qualificação do conhecimento político dos cidadãos. Obviamente, isso está de acordo com a própria missão institucional das mídias legislativas. Mesmo assim, não deixa de caracterizar um aspecto importante em suas práticas, direcionadas para a informação política de interesse público.

Ao adotarem os critérios da produção jornalística convencional, as mídias legislativas procuram obter credibilidade para a sua atividade e rechaçar a ideia de que seriam "mídias oficiais" ou "chapa-branca". Dessa forma, a atividade profissional de seus jornalistas passaria a ser respeitada não somente pelo público, mas também pelos demais produtores de mídia. De certa forma, é uma estratégia de sobrevivência para veículos que almejam o título de jornalísticos e não apenas institucionais.

Apesar de contrariar as intenções de controle direto dos parlamentares, essa estratégia é uma tentativa de separação entre as atividades jornalísticas 
e de relações públicas. E acreditamos que é uma ação mais eficaz do ponto de vista de influência sobre a opinião pública para os próprios deputados, ainda que impeça o controle direto deles na gestão de suas imagens ou na imagem da Câmara. Pelo simples motivo de que a visibilidade em um veículo jornalístico tem maior credibilidade do que o aparecimento em um veículo apenas institucional.

A credibilidade da atividade jornalística consiste, exatamente, na sua autonomia em relação aos poderes estabelecidos. Deixar a atividade informativa das mídias legislativas sob o controle direto dos parlamentares, sem a intervenção jornalística, pode ampliar a visibilidade imediata deles nos veículos, mas certamente diminuiria a credibilidade e, consequentemente, a visibilidade dos veículos no panorama midiático nacional. O que, provavelmente, não serviria aos objetivos finais nem de deputados, nem de jornalistas.

\section{Referências bibliográficas}

AMARAL, Márcia Franz. 2002. "Fontes jornalísticas: o lugar de fala do cidadão". Trabalho apresentado no Núcleo de Pesquisa em Jornalismo, XXV Congresso Anual em Ciência da Comunicação. Salvador/ BA, 4 e 5 de setembro.

BARROS, Antonio Teixeira de; BERNARDES, Cristiane Brum \& LEMOS, Cláudia Regina. 2010. "Programação e audiência de uma emissora legislativa: o caso da TV Câmara". Trabalho apresentado no IV Congresso Brasileiro Científico de Comunicação Organizacional e de Relações Públicas - Abrapcorp, Porto Alegre/RS. Anais (on-line) do IV Congresso Brasileiro Científico de Comunicação Organizacional e de Relações Públicas - Abrapcorp. São Paulo: Abrapcorp.

BERNARDES, Cristiane Brum. 2010. Política, institucional ou pública? Uma reflexão sobre a mídia legislativa da Câmara dos Deputados. Tese de Doutorado. Rio de Janeiro/Brasília/DF: IESP-UERJ/Centro de Formação, Treinamento e Aperfeiçoamento (Cefor) da Câmara dos Deputados.

\& BARROS, Antonio Teixeira de. 2007. "A mídia legislativa como estratégia de conexão eleitoral dos parlamentares brasileiros: o caso da Câmara dos Deputados". Trabalho apresentado no 31 ${ }^{\circ}$ Encontro Anual da Associação Nacional de Pós-Graduação e Pesquisa em Ciências Sociais. Caxambu, 22 a 26 de outubro.

CAPPELLA, Joseph N. \& JAMIESON, Kathleen Hall. 1997. Spiral of cynicism: 
the press and the public good. New York/Oxford: Oxford University Press. CHARAUDEAU, Patrick. 2006. Discurso político. São Paulo: Contexto. COOK, Timothy. 1986. "House members as newsmakers: the effects of televising Congress". Legislative Studies Quarterly, v. 11, n. 2, p. 203-226. GOMES, Wilson. 2004. Transformações da política na era da comunicação de massa. São Paulo: Paulus.

HACKETT, Robert A. 1993. "Declínio de um paradigma? A parcialidade e a objectividade nos estudos dos media noticiosos". In: TRAQUINA, Nelson (org.). Jornalismo: questões, teorias e "estórias". Lisboa: Vega Ltda.

MANIN, Bernard; PRZEWORSKI, Adam \& STOKES, Susan C. 2006. "Eleições e representação". Lua Nova, n. 67, p. 105-138.

MARBUT, Frederick B. 1971. News from the capital: the story of Washington reporting. Carbondale/Illinois: Southern Illinois University Press.

MICHELS, Robert. 1982. Sociologia dos partidos políticos. Brasília: Editora UnB.

MIGUEL, Luis Felipe. 2004. "Modelos utópicos de comunicação de massa para a democracia". Comunicação \& Política, v. 22, n. 3, p.129-147. . 2010. “A mídia e o declínio da confiança na política”. In: MIGUEL, Luis Felipe \& BIROLI, Flávia (orgs.). Mídia, representação e democracia. São Paulo: Hucitec.

\& BIROLI, Flávia. 2010a. "Comunicação e política: um campo de estudos e seus desdobramentos no Brasil” In: MIGUEL, Luis Felipe \& BIROLI, Flávia (orgs.). Mídia, representação e democracia. São Paulo: Hucitec. . 2010b. "O caleidoscópio convexo: visibilidade, meios de comunicação e campo político no Brasil”. Trabalho apresentado no XIX Encontro da Compós. Rio de Janeiro, 8 a 11 de junho.

. 2010c. "Visibilidade na mídia e campo político no Brasil". Dados, v. 53 , n. 3, p. $695-735$.

MUGNATTO, Sílvia \& BERNARDES, Cristiane Brum. 2010. "Estratégias de programação da Rádio Câmara”. Trabalho apresentado no XXXIII Congresso Brasileiro de Ciências da Comunicação. Caxias do Sul/, 2 a 6 de setembro.

NEVEU, Érik. 2006. Sociologia do jornalismo. São Paulo: Edições Loyola. QUEIROZ, Dulce. 2007. Jornalismo institucional nas TVs legislativas. Os casos do Brasil e do México. Dissertação de Mestrado. Brasília: Programa de Pós-Graduação da Faculdade de Comunicação Social, UnB. 
ROBINSON, Michael J. 1981. "Three faces of congressional media”. In: MANN, Thomas \& ORNSTEIN, Norman (eds.). The new Congress. Washington/DC: American Enterprise Institute.

RODRIGUES, Adriano Duarte. 1993. "O acontecimento". In: TRAQUINA, Nelson (org.). Jornalismo: questões, teorias e "estórias". Lisboa: Vega Ltda. SANT'ANNA, Francisco. 2008. Mídia das fontes: o difusor do jornalismo corporativo. Brasília: Casa das Musas.

WEBER, Maria Helena. 2007. "Comunicação pública e a captura do voto”. Trabalho apresentado no XXXI Encontro Anual da Associação Nacional de Pós-graduação e Pesquisa em Ciências Sociais. Caxambu, 22 a 26 de outubro.

\title{
Resumo
}

O artigo utiliza diferentes tipos de dados para analisar a visibilidade que os deputados federais têm nas mídias legislativas mantidas pela Câmara dos Deputados. A disputa pelo controle da produção comunicativa nesses veículos e a tensão entre os critérios políticos e jornalísticos são os dois focos principais na reflexão. Apesar de garantirem a aparição dos deputados, os veículos da Câmara dão mais espaço para os detentores de algum tipo de poder institucional. Os dados mostram que jornalistas e parlamentares disputam o controle dos enfoques das coberturas e da seleção de temas e fontes cotidianamente. E levam à conclusão de que as práticas das mídias legislativas tentam seguir a lógica jornalística na busca de maior credibilidade para as informações veiculadas.

Palavras-chave: Visibilidade política; mídias legislativas; produção jornalística; Câmara dos Deputados; Brasil.

\begin{abstract}
This paper uses different types of data to analyze the visibility that the representatives have in the legislative media maintained by the Chamber of Deputies. The dispute over control of the communicative production of these media and the tension between political and journalistic criteria are the two main focuses. Although they ensure the appearance of representatives, the media give more space for the holders of some kind of institutional power. Data show that journalists and parliamentarians vie for control of the approaches and selection of themes and journalistic sources daily. And lead to the conclusion that the practice of legislative media attempts to follow the logic of journalism in the pursuit of credibility for the information published.
\end{abstract}

Key words: Political visibility; legislative media; journalistic production; Chamber of Deputies; Brazil

Recebido em março de 2011.

Aprovado em junho de 2011. 